\title{
Assessing the Potential of Remote Sensing to Discriminate Invasive Seriphium Plumosum from Grass
}

\author{
Bambo Dubula, Solomon Gebremariam Tefsamichael, Isaac Tebogo Rampedi \\ Department of Geography, Environmental Management and Energy Studies, University of \\ Johannesburg, Johannesburg, South Africa, 201378775@ student.uj.ac.za; +2779 3426815 \\ http://dx.doi.org/10.4314/sajg.v5i2.8
}

\begin{abstract}
The usefulness of remote sensing to discriminate Seriphium plumosum from grass using a field spectrometer data was investigated in this study. Analysis focused on wavelength regions that showed potential of discriminating $S$. plumosum from grass which were determined from global pair spectral comparison between $S$. plumosum and grass. Assessment of reflectance differences done at individual and plot levels using original spectra and spectra simulated based on bands of Landsat and SPOT 5 images. The simulations were done to investigate the possibility of extending field based information into airborne and spaceborne remote sensing techniques. Results showed reflectance spectra of S. plumosum and grass to be relatively comparable. Comparisons at all levels of analysis using original spectra did not show noteworthy reflectance difference in all regions used in the analysis. Similarly, simulated spectra did not show significant differences. The results therefore did not appear to encourage the potential of upscaling the application to airborne and spaceborne remote sensing techniques. There were, however, some shortcomings that made it difficult to draw conclusive remarks on whether the plant can be differentiated from grass. These included, firstly, not all species were in the same phenology. Secondly, spectral measurements were not necessarily taken in an ideal scenario of optimal sunny conditions. It is therefore advised that a similar study be carried out that will address the shortcomings of this study. Furthermore, studies on the biochemical composition of both S. plumosum and grass species are needed, since they explain spectral properties of plants.
\end{abstract}

\section{Introduction}

Seriphium plumosum is an aggressive grass encroacher formerly known as Stoebe vulgaris (Snyman, 2012a, 2010). Although the plant is indigenous to South Africa, it has become naturalised in some parts of Africa (Angola, Madagascar Mozambique, Namibia, and Zimbabwe) and the USA (Snyman, 2012b). The species encroaches Fynbos and Grassland Biomes of South Africa in localities of the Eastern Cape, Free State, Mpumalanga, North West and Gauteng provinces (Snyman, 2012b). Generally, the species encroaches and proliferates in disturbed or overgrazed areas including grasslands in good condition, with reported rapid spread in farms (Eldridge et al., 2013; Snyman, 2012a, 2012b, 2010). 
Infestation by the species results in reduced grass productivity, altered habitat value, altered availability of soil nutrients and soil water, including functions carried out by soil such as respiration, decomposition and infiltration (Eldridge et al., 2013; Snyman, 2010). Such and other effects of the species have led for it to be proclaimed as encroacher in the Conservation of Agricultural Resources Act (CARA) legislation in South Africa (Snyman, 2012a, 2012b). Currently, control of infestations by the species depends mainly on mechanical and chemical methods (Jordaan, 2009; Snyman, 2012b). These control methods have certain limitations which include, amongst others, inaccessibility of infested areas as a result of rough terrain and absence of temporal and spatial distribution maps of the species for development of efficient management strategies (Jordaan, 2009). Such limitations necessitate establishment of inexpensive and effective control methods for this species. Spatio-temporal distribution maps showing dynamics of infestations by the species can help improve efficiency of the currently used control measures.

Mapping is a useful tool that provides information on spatial and temporal distribution of plants including invasive plant species and allows development of better management strategies. In a number of mapping methods, remote sensing is the best due to cost effectives, time efficiency and ability to cover large spatial areas (Hawthorne et al., 2015; Lu and Zhang, 2013; Rodgers et al., 2014). Remote sensing is the science of acquiring information about an object without being in direct contact with it by interpreting different responses of objects to electromagnetic radiation illumination (Alparone et al., 2015; Campbell and Wynne, 2011; Jensen, 2014). As a result, plants have been mapped and discriminated with mixed levels of success using both multispectral and hyperspectral remote sensing techniques (e.g. Abdel-Rahman et al., 2014; Azong et al., 2015; Dronova et al., 2015; Gavier-pizarro et al., 2012; Ghulam et al., 2014; Jia et al., 2014; Somers et al., 2015). Specifically, the ability of hyperspectral remote sensing to record electromagnetic radiations continuously and at narrow wavelength intervals allows for differentiation of vegetation types that appear similar on multispectral data (Carroll et al., 2008). As such, hyperspectral remote sensing has been applied successfully in a number of studies to characterise plants.

Although hyperspectral remote sensing techniques are capable of identifying subtle differences between vegetation species, they make use of specific bands identified using different classifiers. These bands are narrow and often cannot be isolated from within broadbands of multispectral images. As a result, it is difficult to translate the findings of hyperspectral data analysis into multispectral remote sensing systems. This is critical due to the fact that current applications of hyperspectral remote sensing is predominantly limited to research efforts, despite the significant growth of the system over the past few decades. Multispectral remote sensing on the other hand remains the main source of earth observation applications. As much as possible, research efforts involving analysis of hyperspectral data must therefore factor in the potential of extending findings to multispectral remote sensing. 
This study seeks to identify spectral regions bands for discriminating S. plumosum from grass using a field spectrometer data over a long spectrum. Unlike numerous studies that aimed at identifying suitable individual bands, this study uses spectral regions containing contiguous bands as the basic unit of information source. The main objectives of the study are (1) to determine whether or not $S$. plumosum can be discriminated from grass and (2) to investigate the performance of spectra simulated according to Landsat and SPOT 5 images in discriminating S. plumosum from grass species. The second objective is intended as a preliminary indicator on whether or not spaceborne or airborne sensors could be used in developing spatial distribution map of the species.

\section{Methods}

\subsection{Study Area}

The study was conducted in the Klipriviersberg Nature Reserve in Johannesburg, South Africa (Figure 1). The reserve covers an area of approximately 680 hectares, making it the largest reserve in the City of Johannesburg. It is located in the Klipriviersberg area which is in transition between grassland and savanna biomes in the northern edge of the Highveld (Faiola and Vermaak, 2014). The Highveld climate characterised by temperatures ranging between $17-26^{\circ} \mathrm{C}$ in summer and $5-7^{\circ} \mathrm{C}$ in winter (Kotze, 2002). Three geology types occur in the reserve: volcanic rock (basalt and andesite), quartzites and conglomerates, and dolomites (Faiola and Vermaak, 2014). Vegetation types of the reserve are classified as Andesite Mountain Bushveld and a section of Tsakane Clay Grassland at the flatter southern end (Faiola and Vermaak, 2014). The reserve holds a relatively rich biodiversity of approximately 650 indigenous plant species, 215 bird species, 16 reptile species and 32 butterfly species. Mammals that occur in the reserve include lesser spotted genet, African civet, zebra, red hartebeest, blesbok, springbok, duiker, black wildebeest, porcupines, meerkats and otters.

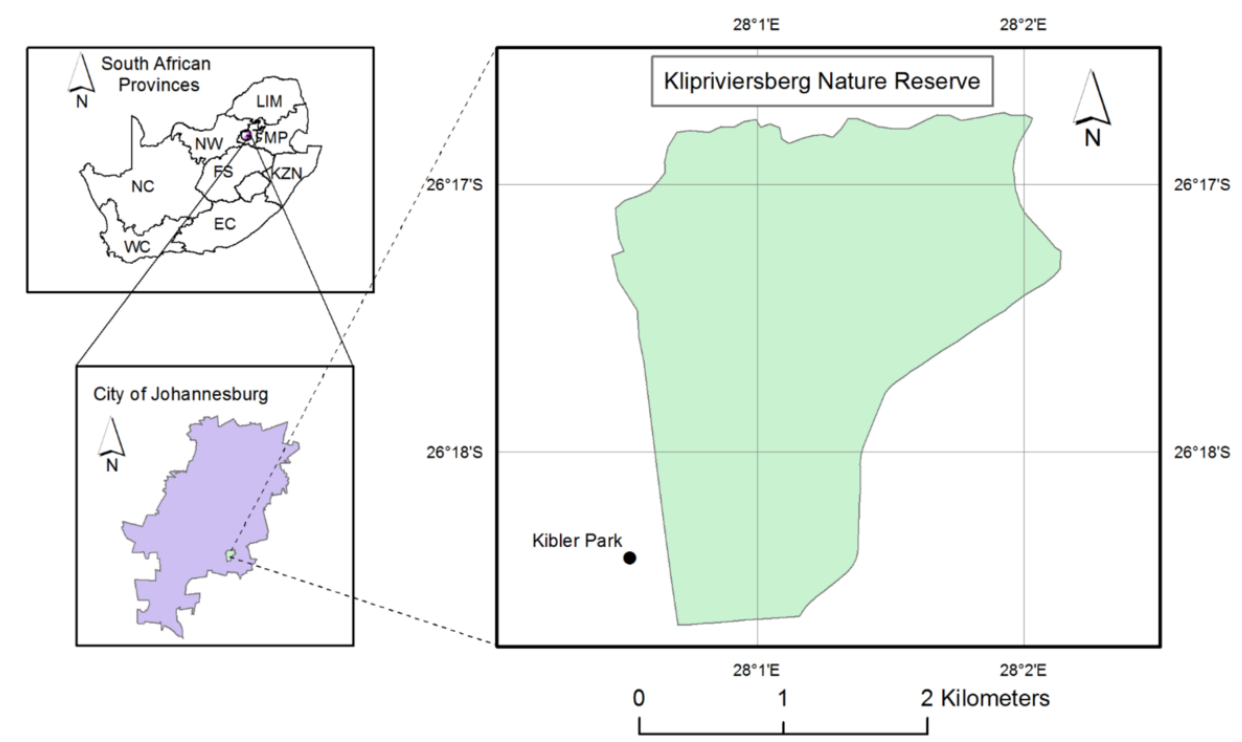

Figure 1. Map showing the Klipriviersberg Nature Reserve 


\subsection{Field Data}

Field surveys were conducted within the summer season between the $2^{\text {nd }}$ and $14^{\text {th }}$ of December 2014. This is the time when vegetation is green and it is the most preferred time for remote sensing applications on vegetation. S. plumosum infestations occur in scattered patterns which limited the number and size of samples and only fifteen stands that had the species were identified. As a result, fifteen plots of a radius of $2 \mathrm{~m}$ circle with fairly considerable concentration of S. plumosum were identified and delineated. The size of the circle was adequate to accommodate imagery with high spatial resolution such as SPOT imagery that has $1.5 \mathrm{~m}$ spatial resolution. A global positioning system (GPS) was used to record the position of each plot. Subsequently, line transects were laid between the centre and the periphery of the plot in each of the north, south, east and west directions. Spectral reflectance measurements of individual plants of $S$. plumosum and adjacent grass were taken at the centre and at $2 \mathrm{~m}$ distance along each transect (Figure 2). In cases where no individual S. plumosum was not encountered along the transect line, one that was placed closest to the transect was sampled.

Spectra were collected using a field spectrometer, namely, Spectral Evolution SR-3500 Remote Sensing Portable Spectroradiometer (Spectral Evolution Inc., Lawrence, MA, USA). The spectrometer has $1.6 \mathrm{~nm}$ spectral resolutions that range between $340 \mathrm{~nm}$ to $2503 \mathrm{~nm}$. Target radiance in energy units was converted into percent reflectance using a white reference measurement. (Prospere et al., 2014). Three spectral measurements were taken from individual $S$. plumosum plant and grass in close proximity. These measurements were taken from different canopy parts of the plant at nadir, under sunny conditions. Such conditions are best achieved at local noon time. This position permits attaining most of the reflected electromagnetic radiation (Cho et al. 2008; Fernandes et al. 2013; Mansour 2013; Olsson et al. 2011; Rudolf et al. 2015). However, not all measurements were taken using this protocol due to time constraint of the study that forced data acquisition outside of the ideal time.

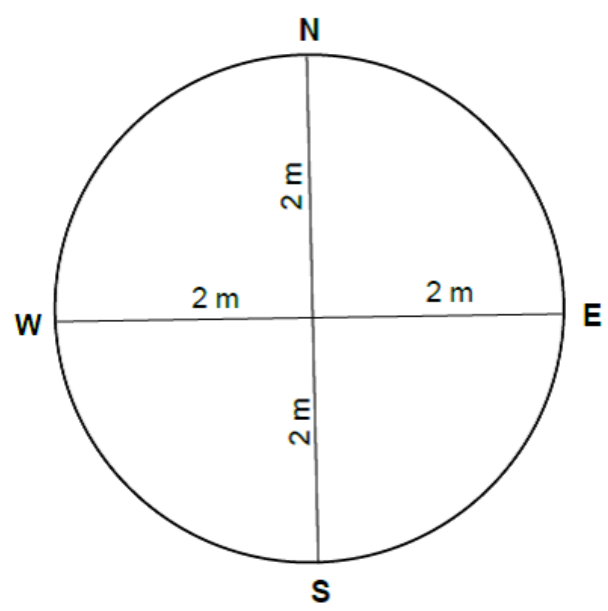

Figure 2. A layout of sampling design for spectral measurements of individual target plant 


\subsection{Analysis of Spectral Reflectance per Region}

Wavelength regions that were better at differentiating $S$. plumosum from grass were identified. To accomplish this, an average reflectance spectrum was computed from the three spectral measurements taken for each individual plant. Subsequently, an average reflectance was computed from all individual plants of S. plumosum and grass plants to create two 'global' spectral curves, respectively (Figure 3). The separate pools were mainly made to determine if $S$. plumosum could be differentiated from grass using reflectance spectra. Comparing the pairs using global spectral curves offers results that are more representative of the study area. In contrast, comparing each pair separately would yield a plethora of results and complicate choice of a result that would represent all individuals.

Wavelength regions that were not useful in discriminating between the S. plumosum and grass were excluded from further analysis following visual observations of global spectra pair comparisons (Figure 3). Two criteria were used for the exclusions; these are, regions that returned random reflectance properties commonly referred to as noise (1824-2016nm and 2282-2503nm) and those which did not show noticeable spectral reflectance differences between S. plumosum and grass (580-758nm and 1095-1422.2nm). This resulted in four discontinuous regions (Figure 3 ) to be used as reference in further analysis. Region 1 included wavelengths in the ultraviolet to visible $(340-579 \mathrm{~nm})$; region 2 included wavelengths in the near infrared (NIR) (759-1091nm); region 3 included wavelengths in the NIR to shortwave infrared (SWIR) (1425.9-1821nm); and region 4 included wavelengths in the SWIR (2019-2279nm).

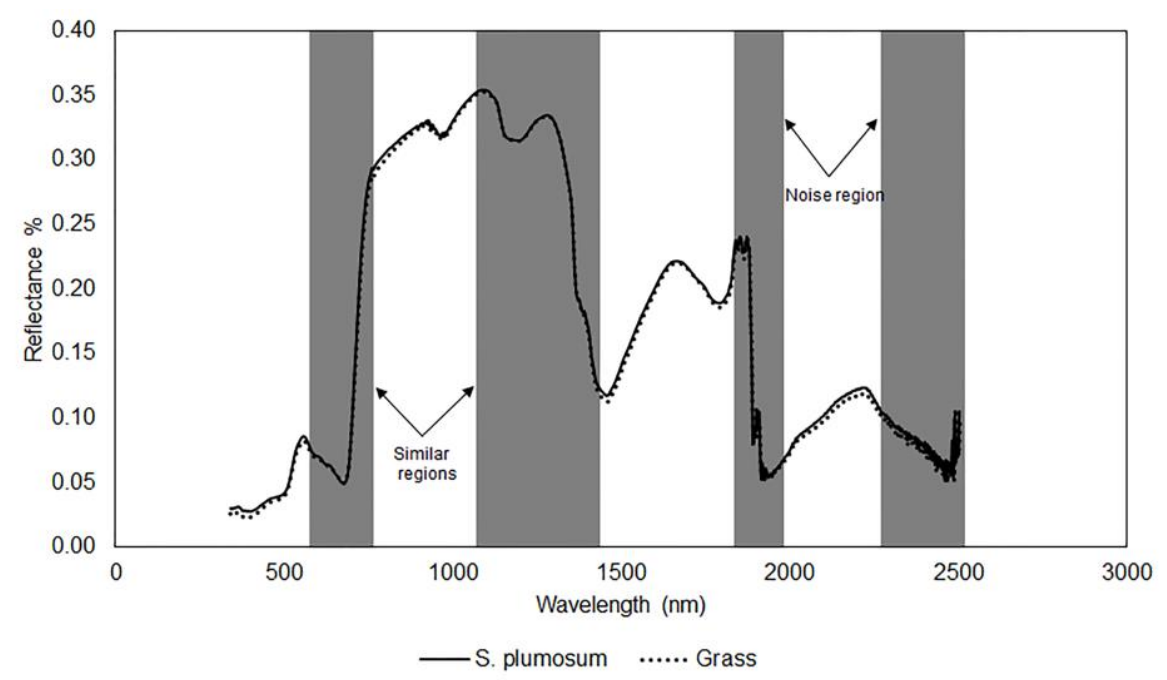

Figure 3. Global reflectance of S. plumosum and grass across the full spectrum. Shaded regions show spectral regions that were excluded from further analysis.

Analysis involved comparisons of S. plumosum and grass reflectance spectra at individual and plot levels. The individual level analysis compared all individual pairs of S. plumosum and grass encountered in each of the plots, while plot level analysis involved comparisons of 
plot level mean reflectance of $S$. plumosum against plot level mean reflectance of grass in all plots. At both levels, analysis was done per region determined from the global reflectance pair comparison (Figure 3). Reflectance spectra were extracted according to these regions. Comparisons were made using graphical and statistical methods. The graphs made use of mean reflectance of all individual plants encountered per plot. Statistical tests involved the use of the analysis of variance (ANOVA) and t-test.

\subsection{Simulation of Landsat and SPOT 5 Imagery Bands}

Although the size of sample plots was not enough to accommodate spatial resolution of Landsat $(30 \mathrm{~m})$, the competence of its bands to discriminate the species were tested. Accordingly, reflectance data acquired from the field spectrometer were extracted according to bands of Landsat and SPOT 5 images. This was done to investigate the potential of upscaling the technique to airborne or satellite based remote sensing. Although Landsat 5 and later missions have seven or more wavebands, only the blue, green, red and NIR bands were simulated, while on the other hand the green, red and NIR bands of SPOT 5 imagery were simulated. These bands have been widely used in studies focusing on remote sensing of vegetation characteristics (e.g. Calvini et al., 2015; Dale et al., 2011; Glenn et al., 2008; Manevski et al., 2011; Pflugmacher, 2007; Tuxen et al., 2008; Xu et al., 2009). Simulations were done for all individuals of $S$. plumosum and grass, resulting in two separate pools per spectral band. Comparisons were made using these pools, and the significance of differences between $S$. plumosum and grass were tested using t-test.

\section{Results}

Comparisons at the individual level showed an overall significant difference between $S$. plumosum and grass in all plots, based on ANOVA results for all individuals per plot. There were, however, within species differences from individual pair comparison per plot using the least significant difference (LSD). Graphical presentation of individual reflectance difference of $S$. plumosum and grass within each plot did not exhibit strong distinction between the two. S. plumosum was fairly discriminated in the NIR to SWIR region (region 3) with eight plots at most showing similarity amongst individuals of $S$. plumosum. Only six plots in NIR (region 2) and SWIR (region 4) regions exhibited similarity amongst individuals of the species, while only three plots showed clear separation in the ultraviolet to visible region (region 1). Figure 4 illustrates a typical plot that shows similarity among individuals of $S$. plumosum and grass, respectively, in the NIR region (region 2) and NIR to SWIR region (region 3).

Plot level results of reflectance comparisons between S. plumosum and grass showed significant difference in all plots. Figure 5 illustrates such a result for a typical plot. Note that results for other plots are not presented here. It is important to note that the differences were not considerable (Figure 5). S. plumosum had slightly high reflectance than grass in 11 plots 
in the ultraviolet to visible region (region 1), 10 plots in the NIR region (region 2) and SWIR region (region 4), with eight plots in the NIR to SWIR region (region 3).

Region 1

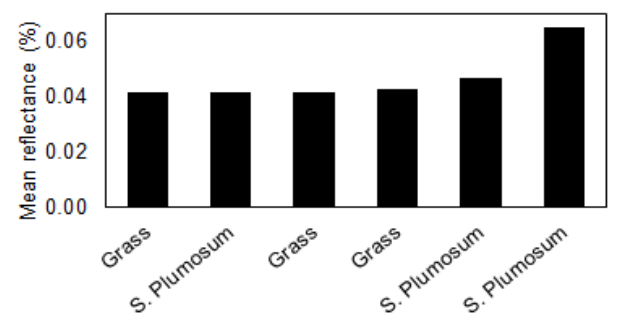

Region 3

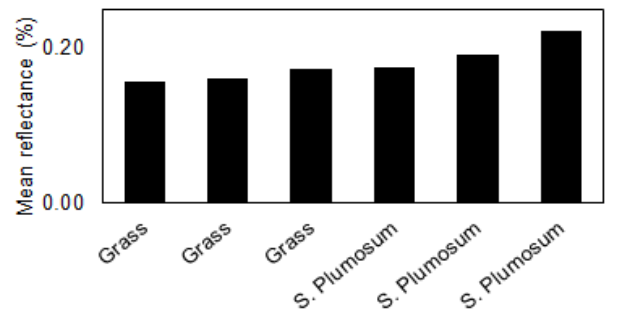

Region 2
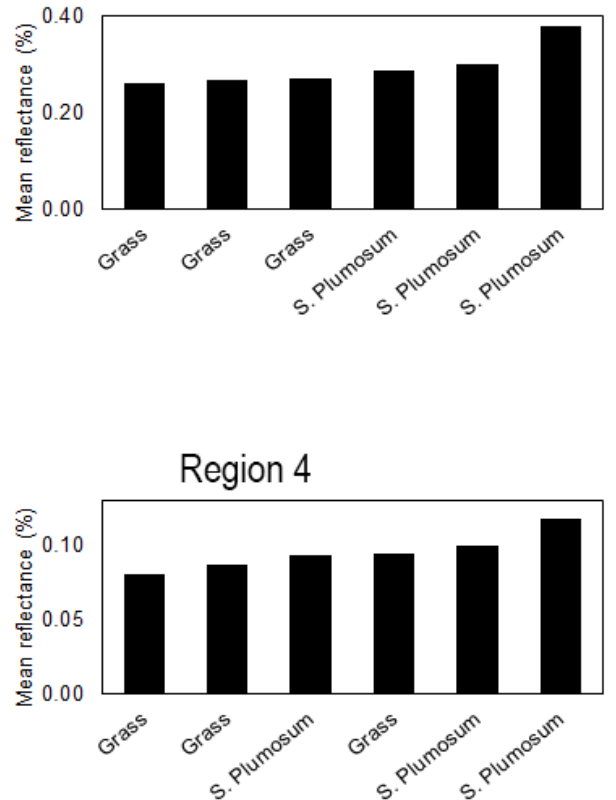

Figure 4. Reflectance of the regions used for analysis at individual plant level for a typical plot at $\alpha=0.05$. Region 1 (Ultraviolet to visible region), region 2 (NIR region), region 3 (NIR to SWIR region), region 4 (SWIR region).
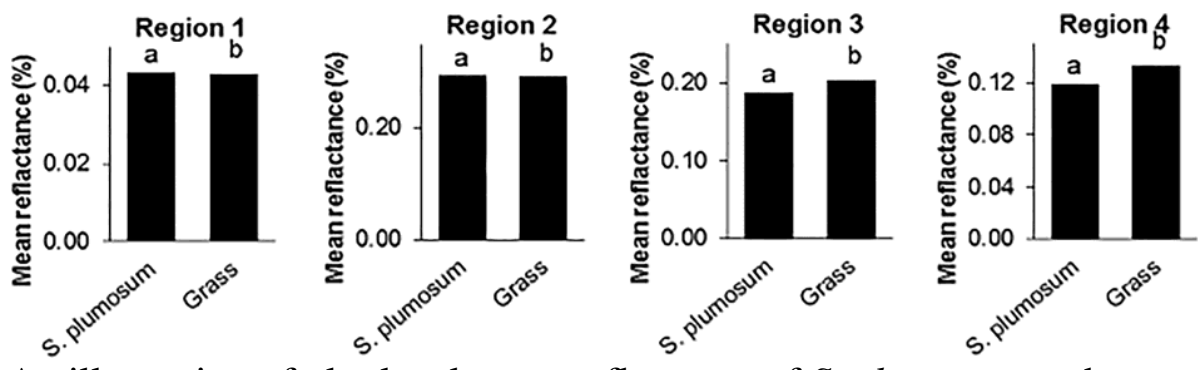

Figure 5. An illustration of plot level mean reflectance of $S$. plumosum and grass. Different letters indicate significant differences at $\alpha=0.05$.

\subsection{Landsat and SPOT Simulations}

The statistical results for reflectance comparisons using Landsat simulated spectra showed significant difference in only the blue band while the differences were insignificant in the other bands (Figure 6). The mean reflectance of all band comparisons between $S$. plumosum and grass were comparable as illustrated in Figure 6. Comparison between S. plumosum and grass using SPOT simulated spectra showed no significant differences in all the bands, as illustrated in Figure 7. 

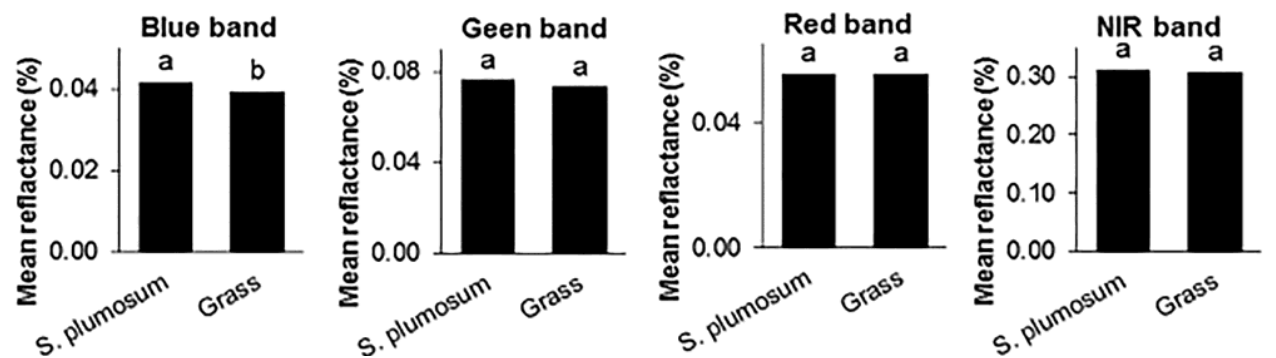

Figure 6. Mean reflectance comparisons of simulated Landsat bands between all S. plumosum and grass individuals. Different letters represent significant differences at $\alpha=0.05$. Note that the comparison are per spectral band.
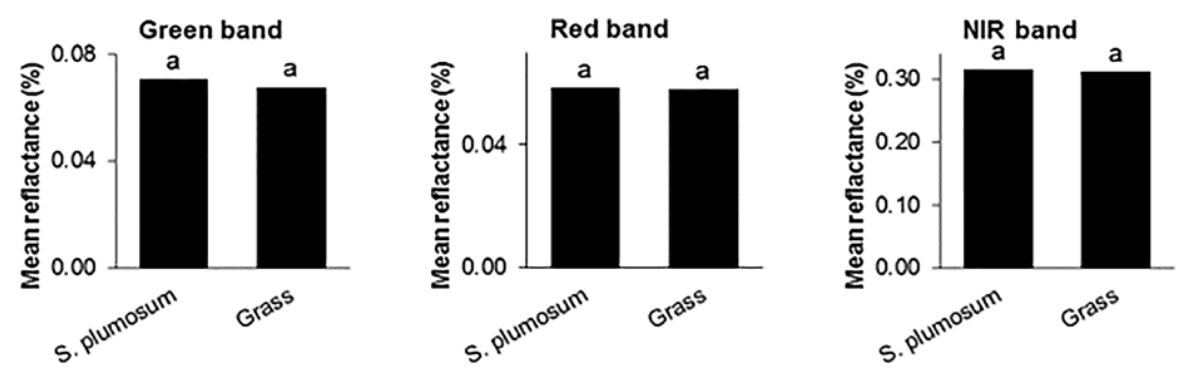

Figure 7. Mean reflectance comparisons of simulated SPOT 5 bands between all S. plumosum and grass individuals. Different letters represent significant differences at $\alpha=0.05$. Note that the comparison are per spectral band.

\section{Discussion}

In this study, the efficiency of data acquired using a field spectrometer to discriminate $S$. plumosum from grass was investigated. Reflectance spectra comparisons were made using original spectra and spectra simulated according to bands of Landsat and SPOT sensors. The simulation was to determine the possibility of upscaling field based data into spaceborne or airborne remote sensing techniques. Visual comparison of the global spectra of S. plumosum and grass were highly comparable, with no distinct spectral separation between the two (Figure 3).

Even though the individual level analysis using ANOVA showed overall significant differences in all plots, these differences were not necessarily the result of reflectance differences between $S$. plumosum and grass individuals per plot. This is because there were within species differences when comparing individual pairs using least significance difference (LSD). Graphical presentation of reflectance differences for all individuals per plot further showed poor separability between S. plumosum and grass. The outcome was not surprising given comparable spectral reflectance patterns of both $S$. plumosum and grass (Figure 4). As such, only eight plots at most in the NIR to SWIR region (region 3) showed best separability between $S$. plumosum and grass, while a few plots showed distinction in reflectance differences between $S$. plumosum and grass, with three plots in the ultraviolet to visible (region 1) and six plots in the NIR (region 2) (e.g. Figure 4). The clear distinction that is observed in the SWIR (region 4) from global pair comparisons was not evident when 
comparing individuals of S. plumosum and grass (Figure 3), only six plots showed clear differences in this region (e.g. Figure 4). Reflectance differences that appear in the first part of ultraviolet to visible reference region (region 1) and NIR reference region (region 2) were not observed in the analysis (Figure 3). Had the analysis not focused on the entire wavelength region of the ultraviolet to visible region (region 1) and the NIR region (region 2) and instead focused on regions that showed distinction (340-335 nm and 759-829 nm), the species could have been clearly differentiated.

Significant differences that were observed at the plot level may not be considered large as illustrated by Figure 5. The slight differences are supportive of poor seperability that is observed in visual comparison of global spectra (Figure 3). These slight differences could have been the result of a number of factors. These include limited number of samples per plot, different phonological stages of $S$. plumosum and grass, as well as taking of spectral measurements under overcast conditions or when there were slight cloud covers. These factors make it uncertain to make conclusive remarks regarding the similarity or disimilarity of reflectance of $S$. plumosum and grass.

The simulation results do not suggest possibility of upscaling of field data into spaceborne and airborne remote sensors such as Landsat and SPOT. Reflectance comparisons using bands simulated according to Landsat showed significant difference only in the blue band, with no significant difference in the green, red and NIR bands (Figure 6). Likewise, reflectance comparisons using simulated bands of SPOT imagery showed no significance difference in the green, red and NIR bands (Figure 7). This was not surprising, given the similarity of global spectra of S. plumosum and grass (Figure 3).

Different classifiers have been used to identify best bands for discriminating between plant species in a number of studies using hyperspectral data. For example, Fernandes et al. (2013) found the visible and the mid infra-red region best at discriminating giant reed (Arundo donax L.) from adjacent vegetation. Abdel-Rahman et al. (2014) found 50 bands located in the red edge $(670-780 \mathrm{~nm})$, blue $(400-500 \mathrm{~nm})$ and green edge $(500-600 \mathrm{~nm})$ of the electromagnetic spectrum of the AISA Eagle image best at detecting Sirex noctilio grey-attacked and lightning-struck pine trees. Dumont et al. (2015) identified 1310nm, 1710nm and 1985nm bands located in the SWIR region as best at identifying viable seeds, empty seeds and seeds infested by Megastigmus sp. Larvae using hyperspectral image and thermal data. Information provided using the technique of selecting specific bands and cannot be extended to broadbands of multispectral remote sensing techniques.

However, the method of analysing continuum spectra in this study made up for the ineffectiveness of selecting specific hyperspectral bands best at differentiating between vegetation species. Because hyperspectral data is not freely available, multispectral remote 
sensing techniques would have been given preference in providing spatio-temporal distribution maps of $S$. plumosum. These are in main realm of earth observation due to the fact that their data are available in public domain. Unfortunately, the species could not be differentiated from grass in this study, most likely as a result of shortcomings that were encountered. As such, the results did not show the potential of extending field based data into airborne or spaceborne remote sensing techniques. Therefore, a same study discriminating S. plumosum from grass needs to be undertaken, using more samples and take all measurements using a standard method (at nadir under sunny conditions) to draw more conclusive remarks on this basis. The suggested study should consider a dry season as well to see if there is a better chance of differentiating the species than in the wet season the current study was undertaken. This should be consolidated by a study profiling biochemical constituents of $S$. plumosum and of any adjacent land cover types (such as grass) in coexistence as biochemical composition of plants strongly affect reflectance patterns (Campbell et al., 2008; Jensen, 2014; Zhang, 2011).

\section{Conclusion}

The potential of field spectral data to discriminate $S$. plumosum from grass was investigated in this study. The study specifically aimed to determine whether or not $S$. plumosum can be discriminated from grass using reflectance spectra. It also sought to test the potential of upscaling field based spectra into airborne and spaceborne remote sensors. Analysis was done using the original spectral and spectra simulated according to bands of Landsat and SPOT imagers, at individual and plot levels. However, spectral discrimination between $S$. plumosum and grass was achieved with limited success. Only a maximum of eight plots showed statistical difference (ANOVA at $\alpha=0.05$ ) at individual level of analysis. Although statistically significant differences (t-test at $\alpha=0.05$ ) were observed at the plot level, they were not large (e.g. Figure 6). Only the blue band of the Landsat simulated spectra proved significant, while there was no significant difference for other bands, including SPOT simulated bands. As such, the results do not suggest a possibility of upscaling field based information into remote sensing technologies such as airborne or spaceborne sensing technologies. A study with enough number of samples is, however, suggested as a follow up study. Such a study would need to consider taking spectral measurements during ideal time frames when there is enough illumination. Other factors that need to be considered are the possibility of stratifying samples based on phenological stages and assessment of biochemical compostion of S. plumosum and grass to draw conclusive remarks on whether they truly share same reflectance pattern. 


\section{References}

Abdel-Rahman, E.M., Mutanga, O., Adam, E., Ismail, R., 2014. Detecting Sirex noctilio greyattacked and lightning-struck pine trees using airborne hyperspectral data, random forest and support vector machines classifiers. ISPRS J. Photogramm. Remote Sens. 88, 48-59.

Alparone, L., Aiazzi, B., Baronti, S., Andrea Garzelli, 2015. Remote Sensing Image Fusion, Signal and Image Processing of Earth Observations. CRC Press.

Azong, M., Malahlela, O., Ramoelo, A., 2015. Assessing the utility WorldView-2 imagery for tree species mapping in South African subtropical humid forest and the conservation implications : Dukuduku forest patch as case study. Int. J. Appl. Earth Obs. Geoinf. 38, $349-357$.

Calvini, R., Ulrici, A., Manuel, J., 2015. Chemometrics and Intelligent Laboratory Systems Practical comparison of sparse methods for classi fi cation of Arabica and Robusta coffee species using near infrared hyperspectral imaging. Chemom. Intell. Lab. Syst. $146,503-511$.

Campbell, J.B., Wynne, R.H., 2011. Introduction to remote sensing, 5th ed. The Guilford Press, New York, United States of America.

Campbell, P.K.E., Middleton, E.M., Corp, L.A., Kim, M.S., 2008. Contribution of chlorophyll fluorescence to the apparent vegetation reflectance. Sci. Total Environ. 404, 433-439.

Carroll, M.W., Glaser, J.A., Hunt, T.E., Sappington, T.W., 2008. Use of spectral vegetation indices derived from airborne hyperspectral imagery for detection of European Corn Borer infestation in Iowa Corn Plots. J. Econ. Entomol. 101.

Cho, M.., Sobhan, I., Skidmore, A.., de Leeuw, J., 2008. Discriminating species using hyperspectral indices at leaf and canopy scales. Int. Arch. Photogramm. Remote Sens. Spat. Inf. Sci. 37.

Dale, L.M., Rotar, I., Bogdan, A., Pacurar, F., Thewis, A., Pierna, J.F., Mukendi, N.K., Beaten, V., 2011. Pure species of grass discrimination with the help of Hyperspectral Imaging NIR. Lucr. ştiinţifice 54, 23-27.

Dronova, I., Gong, P., Wang, L., Zhong, L., 2015. Mapping dynamic cover types in a large seasonally flooded wetland using extended principal component analysis and objectbased classification. Remote Sens. Environ. 158, 193-206.

Dumont, J., Hirvonen, T., Heikkinen, V., Mistretta, M., Granlund, L., Himanen, K., Fauch, L., Porali, I., Hiltunen, J., Keski-saari, S., Nygren, M., Oksanen, E., Hauta-kasari, M., Keinänen, M., 2015. Thermal and hyperspectral imaging for Norway spruce (Picea abies) seeds screening. Comput. Electron. Agric. 116, 118-124.

Eldridge, D.J., Soliveres, S., Bowker, M. a., Val, J., 2013. Grazing dampens the positive effects of shrub encroachment on ecosystem functions in a semi-arid woodland. J. Appl. Ecol. 50, 1028-1038. 
Faiola, J., Vermaak, V., 2014. Klipriviersberg. Veld Flora 68-71.

Fernandes, M.R., Aguiar, F.C., Silva, J.M.N., Ferreira, M.T., Pereira, J.M.C., 2013. Spectral discrimination of giant reed (Arundo donax L.): A seasonal study in riparian areas. ISPRS J. Photogramm. Remote Sens. 80, 80-90.

Gavier-pizarro, G.I., Kuemmerle, T., Hoyos, L.E., Stewart, S.I., Huebner, C.D., Keuler, N.S., Radeloff, V.C., 2012. Monitoring the invasion of an exotic tree (Ligustrum lucidum) from 1983 to 2006 with Landsat TM / ETM + satellite data and Support Vector Machines in Córdoba , Argentina. Remote Sens. Environ. 122, 134-145.

Ghulam, A., Porton, I., Freeman, K., 2014. Detecting subcanopy invasive plant species in tropical rainforest by integrating optical and microwave (InSAR/PolInSAR) remote sensing data, and a decision tree algorithm. ISPRS J. Photogramm. Remote Sens. 88, 174-192.

Glenn, E.P., Huete, A.R., Nagler, P.L., Nelson, S.G., 2008. Relationship between remotelysensed vegetation indices, canopy attributes and plant physiological processes: What vegetation indices can and cannot tell us about the landscape. Sensors 8, 2136-2160.

Hawthorne, T.L., Elmore, V., Strong, A., Bennett-Martin, P., Finnie, J., Parkman, J., Harris, T., Singh, J., Edwards, L., Reed, J., 2015. Mapping non-native invasive species and accessibility in an urban forest: A case study of participatory mapping and citizen science in Atlanta, Georgia. Appl. Geogr. 56, 187-198.

Jensen, J.R., 2014. Remote sensing of the environment: an earth resource perspectivee, 2nd ed. Harlow, Essex: Pearson.

Jia, M., Zhang, Y., Wang, Z., Song, K., Ren, C., 2014. Mapping the distribution of mangrove species in the Core Zone of Mai Po Marshes Nature Reserve, Hong Kong, using hyperspectral data andhigh-resolution data. Int. J. Appl. Earth Obs. Geoinf. 33, 226-231.

Jordaan, D., 2009. Bankruptbush (Slangbos) - A silent threat to grasslands? Grassroots Newsl. Grassl. Soc. South. Africa 9, 40-42.

Kotze, P.., 2002. The ecological integrity of the Klip River and the development of a sensitivity weighted fish index of biotic integrity (SIBI). ujdigispace. University of Johannesburg.

Lu, J., Zhang, Y., 2013. Spatial distribution of an invasive plant Spartina alterniflora and its potential as biofuels in China. Ecol. Eng. 52, 175-181.

Manevski, K., Manakos, I., Petropoulos, G.P., Kalaitzidis, C., 2011. Discrimination of common Mediterranean plant species using field spectroradiometry. Int. J. Appl. Earth Obs. Geoinf. 13, 922-933.

Mansour, K., 2013. Comparing the new generation world view-2 to hyperspectral image data for species discrimination. Int. J. Dev. Res. 3, 8-13. 
Olsson, A.D., van Leeuwen, W.J.D., Marsh, S.E., 2011. Feasibility of invasive grass detection in a desertscrub community using hyperspectral field measurements and Landsat TM imagery. Remote Sens. 3, 2283-2304.

Pflugmacher, D., 2007. Moderate resolution remote sensing alternatives: a review of Landsatlike sensors and their applications. J. Appl. Remote Sens. 1, 012506.

Prospere, K., Mclaren, K., Wilson, B., 2014. Plant Species Discrimination in a Tropical Wetland Using In Situ Hyperspectral Data. Remote Sens. 6, 8494-8523.

Rodgers, L., Pernas, T., Hill, S.D., 2014. Mapping invasive plant distributions in the Florida Everglades using the digital aerial sketch mapping technique. Invasive Plant Sci. Manag. 7, 360-374.

Rudolf, J., Lehmann, K., Große-stoltenberg, A., Römer, M., Oldeland, J., 2015. Field spectroscopy in the VNIR-SWIR region to discriminate between Mediterranean native plants and exotic-invasive shrubs based on leaf tannin content. Remote Sens. 7, 12251241.

Snyman, H., 2010. Allelopathic potential, seed ecology and germination of the encroacher shrub Seriphium plumosum Allelopathic potential, seed ecology and germination of the encroacher. African J. Range Forage Sci. 27, 29-37.

Snyman, H., 2012a. Habitat preferences of the encroacher shrub, Seriphium plumosum. South African J. Bot. 81, 34-39.

Snyman, H., 2012b. Control measures for the encroacher shrub Seriphium plumosum. South African J. Plant Soil 29, 157-163.

Somers, B., Asner, G.P., Martin, R.E., Anderson, C.B., Knapp, D.E., Wright, S.J., Van De Kerchove, R., 2015. Mesoscale assessment of changes in tropical tree species richness across a bioclimatic gradient in Panama using airborne imaging spectroscopy. Remote Sens. Environ.

Tuxen, K.A., Schile, L.M., Kelly, M., Siegel, S.W., 2008. Vegetation Colonization in a Restoring Tidal Marsh : A Remote Sensing Approach. Restor. Ecol. 16, 313-323.

Xu, H., Yu, P., Fu, X., Ying, Y., 2009. On-site variety discrimination of tomato plant using visible-near infrared reflectance spectroscopy *. J. Zhejiang Univ. Sci. B 10, 126-132.

Zhang, Y., 2011. Forest Leaf Chlorophyll Study Using Hyperspectral Remote Sensing. In: Hyperspectral Remote Sensing of Vegetation. CRC Press, pp. 167-186. 